En la etapa de incremento de peso se utilizó el medio MS adicionado con $60 \mathrm{gL}^{-1}$ de sacarosa Esto, basado en uno de los primeros informes relacionados con la microbulbificación sincronizada in vitro en ajos de sanidad controlada, el que fue realizado por Racca (1989) citado por Izquierdo y Quiones (2003). Este autor utiliza como medio basal MS a la mitad suplementado con $0.3 \mathrm{ppm}$ de ANA y $3 \mathrm{ppm}$ de 2 -ip, pero las pérdidas fueron superiores al $70 \%$ cuando se transfirieron las plántulas propagadas in vitro directamente a macetas. Este inconveniente se solucionó transfiriendo las vitroplantas después de la fase de multiplicación a un medio MS diluido a la mitad sin suplemento de auxinas ni citoquininas y suplementado con sacarosa. A los 90 días se obtuvo un $62 \%$ de bulbificación con $60 \mathrm{gL}^{-1}$ de sacarosa. Estos microbulbillos alcanzaron una sobrevivencia superior al $85 \%$ en campo, siempre y cuando su tamaño fuera superior a $3 \mathrm{~mm}$ de diámetro.

Los bulbos obtenidos correspondieron a calibres de bulbos de tamaño floral y sin presencia de raíces; lo que en concordancia con lo señalado por Boutherin y Bron (1994), quienes indican que las raíces nacidas in vitro son extremadamente frágiles y colocadas en contacto con un sustrato, mueren y sería necesario esperar la formación y el crecimiento de nuevas raíces para que la planta se nutra; dejaría material de fácil manipulación para su posterior aclimatación.

Respecto del rendimiento obtenido (número de bulbillos por explante) la tasa fue mayor en explantes provenientes de bulbo. Así también, explantes provenientes de la zona basal de la hoja, tendrían un mayor potencial para generar bulbillos, en relación con explantes provenientes de otras porciones de hoja.

\section{BIBLIOGRAFÍA}

BOUTHERIN, D.; BRON, G. 1994. Multiplicación de plantas hortícolas. Zaragoza, Acribia. 225p.

IZQUIERDO O.; QUIONES O. 2003. Obtención de semilla de ajo. (on line), www.utm.mx/temas/temas-docs/nfnotas15R2.pdf. Marzo 2003.

MANSUR, L.; ZOELLNER, O.; RIEDEMANN, P.; VERDUGO, G.; HARRISON, C. 2002. Leucocoryne, un género nativo chileno y su uso como planta de jardín. Valparaíso, Oficina de Transferencia Tecnológica Universidad Católica de Valparaíso. $49 \mathrm{p}$.

MURASHIGE, T.; SKOOG, F. 1962. A revised medium for rapid growth and bioassays with tobacco tissue cultures. Physiol. Plant. 15: 473- 497.

SCHIAPPACASSE, F.; YAÑES, P.; PEÑAILILLO, P. 1999 Propagación de geófitos nativos. FIA. Los geófitos nativos y su importancia en la floricultura. Talca. 12 noviembre 1999. pp. 11-26.

Agro Sur $34(1-2): 23-252006$

\title{
INDUCCIÓN Y DETECCIÓN DE AUTOPOLIPLOIDÍA EN Rhodophiala Presl.*
}

\section{INDUCTION AND DETECTION OF POLYPLOIDY IN Rhodophiala Presl.}

\author{
Muñoz, $\mathbf{M}^{\prime}$., Riegel, $\mathbf{R}^{1}$. Seemann, $\mathbf{P}^{1}$., Jara, $\mathbf{G}^{1}$., Schiappacasse, F., Peñailillo, $\mathbf{P}^{2}$., Basoalto, $\mathbf{A}^{2}$ \\ 'Instituto de Producción y Sanidad Vegetal, Facultad de Ciencias Agrarias. Universidad Aus- \\ tral de Chile. Casilla 567, Valdivia, Chile. E-mail: mamunoz@uach.cl \\ ${ }^{2}$ Departamento de Horticultura, Universidad de Talca, Casilla 747, Talca.
}

\section{INTRODUCCIÓN Y OBJETIVOS}

La duplicación cromosómica ha sido ampliamente utilizada en horticultura para obtener nuevas y/o mejorar características agronómicas. En especies de uso ornamental esta técnica ha permitido lograr flores de mayor tamaño y de texturas más intensas, así como un período de floración más prolongado. Para realizar un aumento de ploidía en vegetales, es frecuente el tratamiento de plántulas jóvenes en crecimiento activo con colchicina, un alcaloide natural con 
acción antimitótica. Desde los tratamientos de colchicina aplicados in vitro, es posible obtener una población numerosa de plantas, sin embargo, sólo una pequeña fracción de los individuos sobrevivientes a los tratamientos con el alcaloide son efectivamente autopoliploides. El presente trabajo tiene como objetivo dar a conocer los resultados obtenidos en los experimentos de inducción de poliploidía mediante la aplicación de antimitóticos a plántulas jóvenes in vivo e in vitro y en el desarrollo de nuevas técnicas de detección de estos autopoliploides desde una población de plantas tratadas de Rhodophiala.

\section{MATERIAL Y MÉTODOS}

En una primera etapa se realizaron experimentos in vivo a partir de tratamientos a semillas en germinación de $R$. splendens, sometiendo material vegetal de 2 a 10 días luego de la germinación a soluciones de colchicina $0,05 \%$ y $0,2 \%$ por 4 y 12 horas. Luego las plantas fueron cultivadas en macetas con sustrato turba: vermiculita: perlita. Se realizaron recuentos cromosómicos en aplastados de los meristemas radicales tratados con la rección de Feulgen modificada para evaluar el éxito de la inducción. En una segunda etapa se realizaron experimentos in vitro con $R$. monta$n a, R$. splendens, $R$. bagnoldii y $R$. rhodolirion, tratándose plántulas provenientes de semillas germinadas in vitro con soluciones de colchicina al $0,1 \%$ durante 8 horas y $0,2 \%$ durante 4 horas. También se trataron bulbillos in vitro en medio de cultivo líquido Murashigue Skoog adicionado con $0,05 \%$ de colchicina $(\mathrm{p} / \mathrm{v})$ en agitación. El éxito de la inducción se evaluó mediante recuentos cromosómicos en plántulas provenientes de subcultivos de las plantas tratadas. Debido a que la realización de recuentos cromosómicos es un proceso laborioso altamente demandante en tiempo, en una tercera etapa se realizaron investigaciones conducentes a desarrollar nuevas técnicas para la detección de autopoliploides inducidos. Para esto se estudió un grupo de 14 plántulas de $R$. montana, 7 de ellas diploides y otras 7 tetraploides (determinadas mediante recuentos cromosómicos) investigándose la asociación entre el tamaño de estomas y el nivel de ploidía y la aplicación de la técnica de citometría de imágenes para la estimación de la cantidad de ADN nuclear. La estimación de la cantidad de ADN en los núcleos celulares se realizó con las mismas preparaciones citológicas antes descritas. De ellas se obtuvieron 3 a 4 nuevas microfotografías en escala de grises, desde las cuales se midieron un total de 15 núcleos en estado de interfase por planta. Utilizando el programa computacional UTHSCSA Image Tool (disponible en http:// ddsdx.uthscsa.edu/dig/itdesc.html) se obtuvo el valor Integral de Densidad Óptica (IOD). Este valor IOD, considera el tamaño e intensidad de pigmentación de cada núcleo teñido con la reacción Feulgen.

\section{RESULTADOS Y DISCUSIÓN}

Se logró la inducción de poliploidía en $R$. splendens y $R$. montana. Los resultados de la inducción de poliploidía in vivo en $R$. splendens se muestran en os Cuadros 1, 2 y 3 .

En cuanto al estudio del tamaño de estomas y citometría de imágenes en 14 plantas de $R$. montana los resultados muestran que si bien las plantas poliploides en promedio tienen estomas de mayor tamaño, no es posible discriminar el nivel de ploidía en forma individual del $100 \%$ de las plantas, debido a que los valores obtenidos no reflejan una clara separación entre los dos grupos. El análisis citométrico de las imágenes obtenidas de los núcleos de los individuos diploides arroja como promedio un contenido relativo de ADN de 12,83+1,34 millones (valor IOD sin unidad) y de 24,10 $\pm 1,62$ millones para los individuos poliploides. Concordante con la teoría de la duplicación del contenido de ADN en el caso de individuos autotetraploides estos presentan un valor cercano al doble $(1,88)$ del contenido de ADN que las plantas diploides. El promedio IOD de las plantas diploides más 2 veces su desviación estandard (15,51 millones) y el promedio de los poliploides menos 2 veces su desviación estandard (20,86 millones) pueden ser utilizados como parámetros de selección con un $100 \%$ de eficiencia.* 
Cuadro 1. Inducción de poliploidía in vivo en $R$. splendens.

Table 1. Induction of in vivo polyploidy in $R$. splendens

\begin{tabular}{lccccc}
\hline Tratamiento & $\begin{array}{c}\text { Sobrevivencia } \\
\%\end{array}$ & $\mathrm{~N}^{\circ}$ Analizadas & $\begin{array}{c}\text { Poliploides } \\
\%\end{array}$ & $\begin{array}{c}\text { Mixoploides } \\
\%\end{array}$ & $\begin{array}{c}\text { Diploides } \\
\%\end{array}$ \\
\hline $0.05 \%$ col. $\times 4 \mathrm{~h}$ & $69 \%$ & 18 & $11 \%$ & $33 \%$ & $67 \%$ \\
$0.05 \%$ col. $\times 12 \mathrm{~h}$ & $40 \%$ & 5 & $20 \%$ & 0 & $80 \%$ \\
$0.2 \%$ col. $\times 4 \mathrm{~h}$ & $21 \%$ & 5 & $60 \%$ & $40 \%$ & 0 \\
$0.2 \%$ col. $\times 12 \mathrm{~h}$ & $0.05 \%$ & 1 & 0 & 0 & $100 \%$ \\
Testigo & $100 \%$ & & & & \\
10 uM trif $\times 24 \mathrm{~h}$ & $66 \%$ & 17 & 0 & $12.5 \%$ & $58.3 \%$ \\
100 uM trif $\times 24 \mathrm{~h}$ & $41 \%$ & 19 & $5.2 \%$ & $15.7 \%$ & $78.9 \%$ \\
\hline
\end{tabular}

Cuadro 2. Inducción de poliploidía aplicando colchicina in vitro a $R$. splendens

Table 2. Polyploidy induction applying colchicine to $R$. splendens in vitro

\begin{tabular}{ccccccc}
\hline Tratamiento & $\mathrm{N}^{\circ}$ & $\begin{array}{c}\text { Sobrevivencia } \\
\text { Tratadas }\end{array}$ & $\begin{array}{c}\mathrm{N}^{\circ} \\
\text { Analizadas }\end{array}$ & $\begin{array}{c}\text { Poliploide } \\
\%\end{array}$ & $\begin{array}{c}\text { Mixoploides } \\
\%\end{array}$ & $\begin{array}{c}\text { Diploides } \\
\%\end{array}$ \\
\hline $0.1 \% \times 8 \mathrm{~h}$ & 68 & 83 & 12 & 0 & 25 & 75 \\
$0.2 \% \times 4 \mathrm{~h}$ & 69 & 64 & 14 & 20 & 33 & 46 \\
\hline
\end{tabular}

Cuadro 3. Inducción de poliploidía aplicando colchicina in vitro a $R$. montana

Table 3. Polyploidy induction applying colchicine to $R$. montana in vitro

\begin{tabular}{ccccccc}
\hline Tratamiento & $\begin{array}{c}\text { No } \\
\text { Tratados }\end{array}$ & $\begin{array}{c}\text { Sobrevivencia } \\
\%\end{array}$ & $\begin{array}{c}\mathrm{N}^{\circ} \\
\text { Analizado }\end{array}$ & $\begin{array}{c}\text { Poliploide } \\
\%\end{array}$ & $\begin{array}{c}\text { Mixoploides } \\
\%\end{array}$ & $\begin{array}{c}\text { Diploides } \\
\%\end{array}$ \\
\hline $0.1 \times 8 \mathrm{~h}$ & 312 & 33 & 10 & 20 & 0 & 80 \\
$0.2 \times 4 \mathrm{~h}$ & 312 & 44 & 10 & 20 & 0 & 80 \\
$0.05 \times 5 \mathrm{~d}$ & 60 & 60 & 31 & 38 & 19 & 41 \\
\hline
\end{tabular}

\section{BIBLIOGRAFÍA}

COHEN, D.; YAO, J. 1991. In vitro chromosome doubling of nine Zantedeschia cultivars. Plant Cell, Tissue and Organ Culture 47: 43 - 49.

HARDIE, D., GREGORY, R.; HERBERT, D. 2002:
From pixels to picograms: A beginners' guide to genome quantification by Feulgen Image analysis densitometry. The Journal of Histochemistry and Cytochemistry 50: $735-749$

*Trabajo Financiado por Proyecto FIA-BIOT-01-071 